\title{
A formação em educação no Brasil: a sua trajetória e as tendências atuais
}

\section{The education training in Brazil: your history and current trends}

\author{
Alexandre Scherer ${ }^{1}$ \\ Deninson Nunes Ferenci ${ }^{2}$ \\ Paulo Rafael Brum Pedroso ${ }^{3}$ \\ Ronaldo Robinson Martinez ${ }^{4}$ \\ Francielli Teixeira Berto ${ }^{5}$
}

\section{RESUMO}

Este estudo é de característica bibliográfica e faz uma revisão histórica e política da educação centrada na análise da formação para a intervenção profissional. O estudo foi realizado nos anos de 2014, 2015 e 2016 e utilizou livros de referência histórica, artigos indexados em revistas das áreas, documentos oficiais dos Ministérios da Educação leis e resoluções que influenciaram as políticas públicas no Brasil. O texto analisa a história da educação e da formação de professores. O período analisado se estende da época colonial até a atualidade. Conclui-se que as concepções histórico-políticas que orientaram as formações de professores e de profissionais da saúde foram de cunho técnico e de conhecimentos específicos, sustentadas numa concepção neoliberal de mundo que prevê a educação como um produto comercial da sociedade moderna. A formação de professores atualizada aponta para um ensino mais reflexivo que envolve a epistemologia da prática como fundamento básico para se compreender os contextos escolares.

\section{PALAVRAS CHAVE}

Formação; Educação; História da educação.

\footnotetext{
${ }^{1}$ Centro Universitário Metodista, do IPA.

${ }^{2}$ Centro Universitário Metodista, do IPA.

${ }^{3}$ Centro Universitário Metodista, do IPA

${ }^{4}$ Docente de Escola Pública.

${ }^{5}$ Acadêmica do curso de Educação Física do Centro Universitário Metodista - IPA.
} 


\section{ABSTRACT}

This study has a bibliographic feature and makes a historical and political review of the education focused on the analysis of training for professional intervention. The study was realized in 2014, 2015 and 2016 and used historical reference books, articles that were indexed in the area magazines, official documents of Education Ministries, laws and resolutions that influenced the public politicy in Brazil. The text analyzes the history of education and of the teacher training. The period analyzed extends from the colonial era to the present. Concludes that the historical-political conceptions that guided the training of teachers and health professionals were from technical nature and specific knowledge, based on a conception neoliberal of a world that predict the education as a commercial product of the modern society. The teacher training update points a more reflective teaching that involves the epistemology of practice as basic foundation to understand the school settings.

\section{KEY-WORDS}

Teaching; Education; History of Education. 


\section{INTRODUÇÃO}

A educação é uma área de pesquisa e de intervenção profissional que se habilita dentro das políticas públicas como prioritárias para a qualidade de vida ampliada de uma população e de maior justiça social de uma nação. Nesta perspectiva, este projeto compreende que este tema depende de uma política de formação para que sejam efetivadas ações em prol da população brasileira.

Neste sentido, o problema de pesquisa foi definido da seguinte forma: Como se caracterizam as concepções de formação que se desenvolveram e se desenvolvem historicamente no Brasil na área da educação?

Como objetivos do estudo procurou-se compreender quais as principais referências teóricas que influenciam no processo de formação de profissionais das áreas de educação no Brasil; e identificar o percurso histórico que a área da educação têm realizado a sua formação.

Para isso, entretanto, leva-se em consideração que crianças estão fora da escola, que adultos tem dificuldades de acesso a hospitais e que idosos vivem sem um atendimento digno. Os problemas crônicos da falta de qualidade nos processos educativos faz com que a sociedade busque desesperadamente novas formas de atuação e de intervençao, no intuito de solucionar os ploblemas de cada um.

Uma das possibilidades de melhorar a educação brasileira é através da análise da formação que rege as profissões que atuam nesta área. Estabelecer causas e consequências do modo de formação da educação, suas ampliações ou superações na atualidade se constitui no objeto de estudo desta pesquisa que se carcateriza por ser de perspectiva bibliográfica e de cunho qualitativo e objetiva construir um referencial teórico ampliado sobre o tema formação em educação, a construção profissional a partir do ensino superior bem como a compreensão de potencialidades e limitações no mundo trabalho.

Para Marre (1991) a revisão teórica pode ser considerada como uma ruptura com o senso comum, onde o pesquisador sustenta sua proposta, teorias e metodologia sobre o tema estudado.

A pesquisa bibliográfica ou teórica, então, procu- ra estabelecer relações dos conceitos e classificações dos autores relevantes para o tema que possam auxiliar na análise do contexto e do objeto de estudo priorizado naquele momento.

A pesquisa foi realizada através da leitura e interpretação de livros, artigos, leis, resoluções e documentos do Ministério da Educação selecionados que contribuíram com o debate da formação em educação no Brasil desde o período colonial, passando pela república, pelo período militar chegando à abertura política dos anos 1980 e a mais nova legislação brasileira sobre o tema. Esta opção remete a escrita até a contemporaneidade dos autores citados e na configuração das possibilidades de pensar a formação profissional e o mundo do trabalho na atualidade.

Este modelo de pesquisa exige um processo reflexivo que contemple a subjetividade interpretativa considerando tanto a origem do texto como as referências que formam o leitor. Neste sentido, discurso e conteúdo tornam-se sinônimos, pois o instrumento estudado é o próprio referencial teórico que demonstra uma forma de pensar de autores sobre um determinado tema. Neste sentido, Luke (2003, p. 105) afirma que: "A análise do discurso, portanto, emprega técnicas interdisciplinares de análise textual para ver como os textos constroem representações do mundo, das identidades e das relações sociais".

Já Richardson (1999) trata semelhantemente a análise de conteúdo como uma possibilidade de interpretação nas ciências humanas, pois estuda os símbolos e as características da comunicação para compreender o homem, sua história, seu pensamento, sua arte e suas intuições. Segundo o autor, a análise de conteúdo serve para estudar material do tipo qualitativo tentando compreender mais profundamente os discursos e seus momentos mais relevantes.

Para Laville e Dionne (1999) o modelo aberto de análise de dados é indutivo, pois o pesquisador parte de um número de unidades e vai agrupando-as de forma que seus significados sejam aproximados, formando categorias. Nesta fase, estas categorias rudimentares vão servir de ponto de partida para construir as categorias finais do estudo.

Então, de acordo com o objeto e o objetivo do estudo utilizou-se uma categorização temporal co- 
mo processo reflexivo de construção teórica pelo qual se procura dar coerência e consistência ao processo investigativo.

\section{A EDUCAÇÃO NO BRASIL: OS CAMINHOS E OS DESCAMINHOS DE UMA PROFISSÃO DESVALORIZADA}

\section{A Educação e a Formação de Professores na Colônia e na Primeira República}

A história da formação de profissionais no Brasil tem seguido tendências bem distintas desde a sua origem. O processo de elitização que se instaurou no Império do século XVIII no país levava os filhos da burguesia até as universidades europeias para uma experiência formativa e cara, no sentido de atender as necessidades de profissionais para atuarem na administração pública, na saúde e na educação.

Esta situação se refletia na manutenção do poder da gestão pública por uma classe social privilegiada, que cada vez mais desviava recursos para a manutenção do status quo da época. Segundo Ghiraldelli periores foram constituídos no Império com a função de ensinar a ler e a escrever para os cidadãos das grandes metrópoles. O embate da época se dava entre o ideário positivista científico tradicional usando um modelo Lancasteriano que envolvia monitores, inspetores e professores e o projeto humanístico jesuítico onde padres e ordenados eram os professores e que em momentos especiais utilizavam docentes sem formação que não pertenciam à igreja.

Para o autor, ainda não existia uma formação de professores. Qualquer cidadão poderia se alçar ao ofício desde que se sentisse capacitado, aceitasse a livre frequência e tivesse que fazer exames obrigatórios ao final do período letivo.

Pode se afirmar que este modelo tinha sua origem na questão cultural de gestão pública vivida no Brasil naquele momento. Porém, existe a perspectiva de pensar que aquela realidade sentia influências do desenvolvimento de uma educação com viés formativo refletido numa sociedade europeia que já articulava uma manutenção burguesa naquela época.

Então, viram-se espaços públicos como prefeituras e feudos serem administrados por gerações de

famílias ou por uma determinada classe que reproduzia sempre o mesmo modelo: construir riqueza pessoal através da compra de propriedades privadas encaminhando seus filhos para uma formação que se propunha a seguir esta dimensão indefinidamente.

Neste sentido, os recursos públicos daquela época foram articulados para atender uma demanda burguesa de caráter privatista, mas de prática pública, isto é, a escola pertencia ao estado, mas quem a frequentava eram os filhos da classe dominante. Com isso, a maioria da população não se alfabetizava nem construía consciência política.

Não existia, então, interesse em dar educação à classe trabalhadora ou escrava ${ }^{1}$, pois da sua opressão se ampliavam os ganhos da produção agrícola ou da gestão pública. Somente os filhos da classe burguesa tinham instrução no sentido de futuramente tomar o lugar das profissões mais importantes da época.

Observa-se até o momento que a organização educacional brasileira até os anos 1930 aproveitava das instituições de ideologia cristã para desenvolver dois tipos de educação: o primeiro voltado às elites e a manutenção do status quo juntamente com a formação de novas lideranças religiosas; e o segundo ainda não de forma universal no país procurava ensinar conhecimentos e princípios relevantes para uma classe de trabalhadores mais voltados à produção industrial e comercial no Brasil.

Sobre a formação, estas instituições cristãs vão ser as responsáveis pela reprodução de um modelo de professor disciplinador, ideológico, reprodutor das classes diferentes existentes no Brasil.

\section{A Educação na Segunda República}

Esses quatro exemplos somados aos jesuítas que por aqui se encontravam foram relevantes para a formação escolar no Brasil até os anos de 1930. E é a partir deste período, a chamada segunda república, que ocorrem as mudanças e definições mais contundentes da educação nacional. Existe a partir daí um confronto explícito entre os que desejavam uma educação pública, de qualidade, laica e sustentada pelo

1 Mesmo após a abolição da escravatura a educação escolarizada não era permitida a ex-escravos. 
estado, enquanto que, por outro lado, haviam educadores e políticos oriundos das instituições religiosas que desejavam manter as escolas cristãs numa concepção pública a serviço do estado como um serviço essencial para o progresso do País.

Na era Vargas o Brasil teve o primeiro debate mais profundo sobre a educação. Neste período alguns intelectuais se formaram e influenciaram as ideias sobre o tema. A educação sempre foi ligada aos interesses políticos entre dois grupos de pessoas poderosas: uma elite conservadora de direita (a UDN² liderada por Jânio Quadros) em prol de interesses estrangeiros e uma elite socialista e trabalhista (o $\mathrm{PTB}^{3}$ de João Goulart e Getúlio Vargas e o PSD ${ }^{4}$ de Juscelino Kubitscheck) em prol de um trabalho urbano de esquerda (incluindo de certa forma o comunismo) mas voltados ao desenvolvimento interno do Brasil. Neste período começou a se gestar uma Lei de Diretrizes e Bases da Educação Nacional (LDBEN) que foi discutida durante 13 anos em prol do desenvolvimento do país na perspectiva de construir uma cidadania para o trabalho.

A discussão entre o ensino público e privado foi tema central. Neste sentido, três grupos em defesa da escola pública se debateram sobre o tema: Anísio Teixeira sob a influência do pragmatismo de John Dewey, o liberal Roque Spencer Maciel de Barros e outros articulados com as ideias socialistas de Kant e de Florestan Fernandes sob a influência socialista. Estes intelectuais debateram e publicaram uma carta prévia à LDBEN de 1961.

Os intelectuais que se opunham ao ensino público eram liderados por Dom Evaristo Arns da Igreja Católica. Este grupo afirmava que a educação deveria ser uma escolha da família e que o ensino religioso deveria fazer parte do currículo, além de poder ser um negócio lucrativo de acordo com as leis do mercado. O discurso principal argumentava a favor de uma educação pública não estatal ou de interesses privatistas sob a tutela da igreja.

Após a construção da LDBEN de 1961 foi elencado o primeiro Plano Nacional de Educação (PNE) que

2 União Democrática Nacional.

3 Partido Trabalhista Brasileiro.

4 Partido Social Democrático. traçou metas de utilização de $12 \%$ dos impostos arrecadados para a educação além de $100 \%$ de matricula até a $4^{\mathrm{a}}$ série, $70 \%$ de matriculas até a $6^{\mathrm{a}}$ série, $50 \%$ de matricula no ginasial e $30 \%$ de matrículas no colegial.

Neste período a formação de professores e de outros ofícios passava por uma ampliação no ensino superior. Segundo Cacete (2014) havia finalmente um processo organizado através das universidades e faculdades instaladas no Brasil. Sampaio (1991) aponta que algumas das contradições do ensino superior brasileiro são fruto deste período de debate que desemboca na LDBEN onde se nota uma divisão clara entre a formação para as profissões tradicionais e a formação para o incremento da pesquisa nas universidades brasileiras.

O PNE objetivou que o ensino superior deveria atender a $15 \%$ da população nacional. Sobre a formação de professores o documento apontou que até o ano de 1970 os docentes que atenderiam o ensino primário deveriam ser formados $20 \%$ em cursos regentes, $60 \%$ em cursos normais e $20 \%$ cursos de nível pós-colegial. Isto significou que ainda grande parte dos professores voltados a atender as escolas públicas e privadas não tinham uma graduação superior, e sim, uma formação de nível médio.

\section{A Educação e a Formação de Professores no Período Militar}

A educação no período militar instalou uma nova LDB em 1971. Para os novos comandantes do país a política, os partidos e o congresso era um mal em si mesmo e que deveriam ser substituídos por uma estrutura mais tecnocrática. Esta lei dominou a educação nos anos 1970, 1980 e parte de 1990 e as principais características, segundo Ghiraldelli Jr. foram: desprestigiar as classes populares de uma educação de qualidade: ampliar o ensino profissionalizante sem estrutura mínima para esta função: utilizar uma tecnologização dos conteúdos, isto é, usar o racionalismo técnico americano sustentado nas experiências de Skinner proposto por organismos internacionais e referendado pelo acordo entre o Ministério da Educação e Cultura (MEC) e a Agency for International Development (acordo MEC-USAID) que refletiu um pensamento técnico americano não democrático 
mas que serviu aos propósitos de desenvolvimento do país militar num sistema de construção fabril que elitizou o ensino superior e propôs limites sobre a consciência do povo no ensino fundamental e médio, trabalhando exclusivamente elementos práticos.

Este fato significou que o ensino superior manteria a elite com a disseminação e construção de conhecimentos novos enquanto que a população em geral seria encaminhada a um ensino técnico e reprodutor de mão de obra barata, com baixa possibilidade de crítica social.

Sem poder tomar parte efetiva do debate político o professor foi uma figura à margem de quem lhe diz o que fazer, que conteúdo escolher, que metodologia utilizar ficando à mercê de outros conselhos escolares.

Talvez o grande avanço desta época histórica seja a ampliação dos programas de pós-graduação no Brasil que, juntamente com a abertura política e o retorno de intelectuais exilados, vem a construir teorias de resistência aos modelos educacionais concretizados na ditadura militar. Paulo Freire, Rubem Alves, Dermeval Saviani, Darcy Ribeiro e Moacir Gadotti entre outros tantos dialogaram com reflexões desenvolvidas como a teoria da reprodução de Bourdieu e Passeron, a teoria social crítica da Escola de Frankfurt, a epistemologia genética de Piaget e a pedagogia crítica de Giroux, McLaren e Kincheloe, por exemplo.

A entrada destes e de outros intelectuais na universidade brasileira fazem com que a formação de professores debata e discuta a política educacional no intuito de desenvolver uma consciência crítica, acreditando numa mudança social, política e econômica a partir dos movimentos na escola. A ideologia de que a educação e a escola eram instituições neutras estava sendo desafiada a partir da formação dos docentes.

\section{A Legislação Brasileira e a Formação de Professores}

A educação se tornou um dos centros de discussão da Constituição Nacional de 1988 e na construção da LDBEN de 1996. Questões como o financiamento da educação e o modelo de ensino público e privado que se efetivaria a partir estiveram na pauta de debate da década de 1990. As ideias de Perrenoud (1999 e 2000) sobre habilidades e competências e os quatro pilares da educação (aprender a conhecer, aprender a fazer, aprender a viver com os outros, aprender a ser) apresentado pelo Relatório da Comissão Internacional Sobre Educação para o Século XXI, coordenada por Jacques Delors em 1999 são referências muito difundidas no universos acadêmico da época. Nesta visão, uma educação é proposta através da utilização de recursos tecnológicos e da possibilidade se efetivar à distância, onde ao aluno cabe uma gerência sob seu ensino e ao professor uma função de tutor.

Neste sentido, o relatório Delors (2000) compreende e valoriza a força motriz do capital e revela que o principal condicionante do ensino é a formação para o trabalho revelando aí de forma sintética uma adaptação das culturas das nações à globalização através da modernidade e da instrumentalização técnica em prol do capital orientado pelos países ricos.

Para Kuenzer (2002) e Ávila, Muller e Ortigara (2005) o ensino básico brasileiro e, consequentemente, o ensino superior voltado à formação profissional seguem modelos voltados ao mercado de trabalho organizados pelo Banco Mundial (órgão internacional que atua na economia global) e se reflete no controle de conhecimentos específicos básicos necessários à produção como as disciplinas de português e de matemática

As reflexões necessárias para a construção de um cidadão crítico e ativo como se refere Paulo Freire (2003), Peter McLaren (1997) e Henry Giroux (1997), por exemplo, passam longe do sistema escolar tradicional que não se adaptam aos testes impostos pelo Ministério de Educação. Assim se constitui a educação brasileira hoje, caracterizada pelas crianças na escola, muitas delas influenciadas pelo Programa Bolsa Família, mas sem a escola de qualidade que o país tanto precisa.

A LDBEN/1996 levou à construção das Diretrizes Curriculares Nacionais (DCN) para a Educação Básica e da Diretrizes Curriculares para as diferentes formações superiores no Brasil, entre elas a de formação de professores a partir de 2002. Esta última impactou de forma relevante a formação de professores que, em geral no curso superior era feita através de um sistema caracterizado culturalmente de formação $3+1$. Nesta, os primeiros anos eram específicos de uma área: biologia, matemática, história, entre ou- 
tros. Ao final, estava formado um bacharel. $\mathrm{O}$ ano complementar era enriquecido de conhecimentos pedagógicos e estágios que oportunizavam ao bacharel a se licenciar para a intervenção no ensino básico brasileiro.

Ao contrário, as DCN de 2002 afirmavam que a formação teria que ser específica para a docência na escola e não generalista como era feita alterando uma lógica epistemológica que valorizava inicialmente o desenvolvimento da área específica para complementarmente introduzir nos currículos os aspectos pedagógicos e didáticos. Com isso, todas as áreas tiveram que compor novas DCN para formar os seus bacharelados no Brasil. O impacto mais positivo destas resoluções foi a proposta de efetivação de uma epistemologia da prática que é caracterizada por reflexões sobre a profissão docente e suas possibilidades de atuação desde o início dos cursos.

Estas dificuldades foram sendo superadas com novas estratégias de ensino e ampliação cada vez maior da formação de conhecimentos pedagógicos no sentido de formar professores com maior senso crítico a partir do conhecimento da realidade da educação brasileira dentro dos cursos.

Após a proposição de políticas de valorização dos professores como o piso nacional que ainda não é cumprido por muitos estados e municípios, a educação brasileira passou por dois momentos de debate: as Conferencias Nacionais de Educação (CONAE) e o Plano Nacional de Educação (PNE). A CONAE de 2010 decidiu positivamente sobre a elaboração de uma Base Comum Nacional a partir de uma formação teórica e interdisciplinar, nas áreas específicas do conhecimento humano, na unidade entre teoria e prática, na categoria trabalho como função social e na pesquisa como metodologia de aprendizagem. Este debate sustentou a construção das Diretrizes Curriculares Nacionais da Educação Básica (2013) que, entre outras medidas, redefiniu o Sistema Nacional de Educação entre federação, estados e municípios, e definiu as áreas que compõe a Base Nacional Comum com Língua Portuguesa, Matemática, conhecimento do mundo físico, natural, da realidade social e política, especialmente do Brasil, incluindo-se o estudo da História e das Culturas Afro-Brasileira e Indígena, Arte, em suas diferentes formas de expressão, incluindo-se a mú- sica, Educação Física e Ensino Religioso.

A CONAE de 2014 apresentou um indicativo muito relevante no sentido de compreensão do conceito de profissionais da educação ao afirmar que eles são entendidos como os docentes, isto é, professores, que atuam diretamente no ensino e devem ser licenciados para tal, como condição para ingresso na carreira profissional.

Sobre a formação docente o PNE construído em 2014 estabeleceu dentro de suas metas que em 2015 todos os professores da educação básica deveriam ter formação específica em nível superior; que em 2024 , ao findar o plano, 50\% deles tenham pós-graduação em qualquer nível; que até 2020 o salário seja melhorado; e que até 2016 se tenham implantados planos de carreira.

Em 2015 novas DCN para a formação de professores foram aprovadas sob o título de Diretrizes Curriculares Nacionais para a Formação Inicial e Continuada dos Profissionais do Magistério da Educação Básica.

Além dos professores, a Lei ํㅡ. 12.014/2009 que definiu os profissionais da educação escolar básica considerou também que todos os sujeitos envolvidos na escola são participantes, desde que tenham uma formação para tal. Verifica-se, então que houve uma ampliação do conceito de docente na escola. Além deles que devem ter realizado uma formação em licenciatura ficam habilitados a trabalhar na escola outros profissionais que tenham também uma habilitação para tal, como supervisores e orientadores pedagógicos. Todos eles são tratados como profissionais da educação escolar básica.

As disposições gerais tratam da articulação entre o PPC, o PDI, o PPI, as DCN, a LDB, os SINAES 5 e o PNE. Apontam para a preparação na intervenção na educação formal no conceito de docência e ampliam os conhecimentos específicos com outras competências como as diferenças étnico-raciais, os aspectos políticos, a relação teoria-prática e a integração constante com a escola de educação básica.

Consolida a base comum nacional que é caracterizada principalmente pela especificidade do trabalho docente, pela articulação teoria-prática e pelo desen-

5 Sistema Nacional da Avaliação da Educação Superior. 
volvimento de conhecimentos e competências voltados ao pensamento crítico e consciente da realidade nacional e as propostas de superação dos problemas através de um trabalho coletivo e interdisciplinar.

Observa-se que as DCN centradas nos cursos de graduação em licenciatura são encaminhadas para a formação de docentes na educação formal básica, porém, abre possibilidades para a educação não formal. O currículo deve ser dividido em núcleos: núcleo de estudos de formação geral, das áreas especificas e interdisciplinares; núcleo de aprofundamento e diversificação de estudos das áreas de atuação profissional; e núcleo de estudos integradores para enriquecimento curricular. Devem ainda compor o currículo de 3200 horas a prática como componente curricular e os estágios curriculares supervisionados.

A complexidade do curso de formação de professores se amplia de forma que muitos fatores intervenientes definem de maneira diferente e não complementar competências diversas como os fundamentos da educação, a formação política, a gestão escolar, os direitos humanos, a Libras e o direito de jovens em cumprimento de medidas educativas.

Apesar de todo este aparato, ao propor que os cursos de formação de professores utilizem metodologias ativas na inter-relação entre ensino, pesquisa e extensão, as DCN não apontam formalmente para a construção de Trabalhos de Conclusão de Curso diferenciando dos cursos de bacharelado que tem a obrigatória da construção dos conhecimentos no Brasil.

\section{REFLEXÕES SOBRE A FORMAÇÃO DE PROFESSORES NO BRASIL}

Após análise histórica verificou-se que a educação brasileira atravessou um terreno político variado de embates e interesses diversos que pode ser sintetizado entre um modelo de educação reprodutivo, elitista e privatista e um modelo de educação popular, crítico e emancipatório.

A expansão dos sistemas de ensino se evidenciou pela busca de direitos das classes menos privilegiadas além de uma formação mínima para atuar num mercado capitalista e burguês instalado no país desde a primeira república.

A formação de professores acompanhando esta tendência iniciou particularmente dentro de instituições de ensino religiosas que instruíam um tom tradicional, disciplinador e, em alguns momentos com punições físicas. Estas escolas se adaptaram ao modelo burguês, mas não atendiam a população do país como um todo. Somente nas décadas de 1920 e 1930 movimentos em prol de uma educação pública, laica e de qualidade se constituem com teorias inovadoras o que causa um embate entre os setores público e privado, entre as ideologias cristãs e laicas.

Com um tom de modernidade e de desenvolvimento nacional a educação passa por um período repressor e de formação técnica para ampliar a mão de obra fabril dos anos 1960 até 1980 quando, a partir da abertura política e da construção da nova constituição brasileira o tema é retomado de forma a ser pensado como um direito da população e um investimento do estado.

Desde então a formação em educação tem se tornado um desafio para o Conselho Nacional de Educação e entidades representativas da área. Entre 2010 e 2030 teremos uma transição político-pedagógica onde professores formados sob a égide do tecnicismo serão substituídos pelos profissionais da educação formados por diretrizes curriculares orientadas no sentido de ampliar a consciência crítica e a cidadania no Brasil. Espera-se que futuramente crises políticas como as que vivenciamos em 2016 sejam superadas por formas de pensar e agir em prol de uma sociedade coletiva, ética e democrática, mas com valores que levem ao desenvolvimento do fator humano, da qualidade de vida e da equidade social.

\section{FORMAÇÃO EM EDUCAÇÃO NO BRASIL: MANUTENÇÃO OU TRANSFORMAÇÃO?}

Ao estudar a temática nos demos conta de que o tema formação profissional não pode ser abordado sem um estudo contextual da história vivida no Brasil pela área de educação. As concepções que orientaram as formações de professores foram de cunho técnico e de conhecimentos específicos, além da busca constante de especializações e na valorização de profissões autônomas, ligadas ao mundo neoliberal que prevê a educação como um produto comercial que pode ser explorado por editoras no caso da educação ou por 
empresas voltadas especificamente para esta área.

A esperança de mudanças ou de alterações nos últimos anos vem sendo debatida na área da educação a partir da construção e aprovação das Diretrizes Curriculares Nacionais para a formação de professores que apontam para um diálogo com a comunidade no sentido redirecionar um ensino técnico, enraizado no Brasil, em um ensino reflexivo que envolve a epistemologia da prática como fundamento básico para se compreender os contextos escolares desde que os alunos entram na formação inicial. Neste sentido, metodologias mais diretivas e causais propostas por Perrenoud e Delors são debatidas com apontamentos críticos e que envolvem a comunidade escolar trazidas por Paulo Freire, Saviani, Giroux e McLaren.

Enfim, este estudo buscou compreender como ocorre historicamente a formação profissional na área de educação. A partir desta análise observa-se que esta área está sendo cada vez mais distanciada pelas políticas públicas do controle do Estado. Pode-se afirmar que a formação universitária no Brasil tem sofrido influências neste sentido que refletem a identidade profissional para uma intervenção mais técnica e voltada para o mundo do trabalho capitalista. Poucas são as experiências de formação que levam em consideração uma intervenção mais voltada às comunidades carentes. O que se observa são formas de manutenção de atendimentos de maior qualidade às populações de classes mais elevadas através de mecanismos de terceirização, principalmente no ensino superior privado. 


\section{REFERÊNCIAS}

ÁVILA, A. B.; MULLER, H. V. O.; ORTIGARA, V. Formação de Professores e Qualidade da Educação: "direita, volver". In: FIGUEIREDO, Z. C. C. (org.). Formação Profissional em Educação Física e Mundo do Trabalho - volume I. Vitória: Gráfica das Faculdades Salesianas, 2005. p. 71-87.

BRASIL. Constituição (1988). Constituição da República Federativa do Brasil: promulgada em 5 de outubro de 1988. Brasília: Imprensa Oficial da União, 1988. Disponível em: <http://www.planalto.gov.br/ccivil_03/constituicao/ constituicaocompilado.htm >. Acesso em: 22/01/2015.

BRASIL. Lei n 9.394/96. Estabelece as Diretrizes e Bases da Educação Nacional. Lei de Diretrizes e Bases da Educação Nacional. Brasília: MEC, 1996. Disponível em: <http://portal.mec.gov.br/arquivos/pdf/ldb.pdf $>$. Acesso em: 07/10/2015.

BRASIL. Lei $\mathrm{n}^{\circ}$. 12.014, de 6 de agosto de 2009. Altera o art. 61 da Lei no 9.394, de 20 de dezembro de 1996, com a finalidade de discriminar as categorias de trabalhadores que se devem considerar profissionais da educação. Disponível em: < http://www.planalto.gov.br/ccivil 03/_ato20072010/2009/lei//12014.htm >. Acesso em 07/10/2015.

BRASIL. Lei no. 13.005, de 25 de junho de 2014. Aprova o Plano Nacional de Educação - PNE e dá outras providências. Disponível em: <http://www.planalto.gov.br/ccivil_03/_ ato2011-2014/2014/lei//13005.htm >. Acesso em 07/10/2015.

CACETE, N. H. Breve história do ensino superior brasileiro e da formação de professores para a escola secundária. Educação e Pesquisa [online]. 2014, vol. 40, n. 4, pp. 1061 1076. 2014.

CONFERÊNCIA NACIONAL DE EDUCAÇÃO (CONAE), 2010, Brasília, DF. Construindo o Sistema Nacional Articulado de Educação: o Plano Nacional de Educação, diretrizes e estratégias; Documento Final. Brasília, DF: MEC, 2010. Disponível em: <http://Conae.mec.gov.br/images/stories/pdf/pdf/doc_ base_documento_final.pdf >. Acesso em: 7 jun. 2015.

CONFERÊNCIA NACIONAL DE EDUCAÇÃO (CONAE), 2014, Brasília, DF. O Plano nacional de Educação na Articulação do Sistema Nacional de Educação. Documento Final. Brasília, DF: MEC, 2014. Disponível em: < http://conae2014. mec.gov.br/images/pdf/doc_referencia_conae2014.pdf $>$. Acesso em: 7 jun. 2015.
CONSELHO NACIONAL DE EDUCAÇÃO. Conselho Pleno. Resolução $n^{\circ}$. 1, de 18 de fevereiro de 2002. Diário Oficial da União, Brasília, DF, 9 abr. 2002.

DELORS, J. Educação: um tesouro a descobrir. Relatório para a Unesco da Comissão Internacional sobre a Educação para o século XXI. 5. ed. São Paulo: Cortez. 2000.

FREIRE, P. Educação como Prática da Liberdade. 27. ed. Rio de Janeiro: Paz e Terra, 2003.

GHIRALDELLI JÚNIOR, P. Filosofia e história da educação Brasileira. Barueri: Manole, 2003.

GIROUX, H. A. Os Professores Como Intelectuais: rumo a uma pedagogia crítica da aprendizagem. Porto Alegre: Artes Médicas, 1997.

LAVILLE, C.; DIONNE, J. A Construção do Saber: manual de metodologia da pesquisa em ciências sociais. Porto Alegre: Artes Médicas e UFMG, 1999.

LUKE, A. Análise do discurso numa perspectiva crítica. In: HYPÓLITO, Á. L. M.; GANDIN, L. A. (Org.). Educação em Tempos de Incerteza. 2. ed. Belo Horizonte: Autêntica, 2003. p. $93-110$.

KUENZER, A. Z. Exclusão Includente e Inclusão Excludente: a nova forma de dualidade estrutural que objetiva as novas relações entre educação e trabalho. In: LOMBARDI, J. C.; SAVIANI, D.; SANFELICE, J. L. (org.). Capitalismo, Trabalho e Educação. Campinas: Editores Associados, 2002. p. 78-95.

MARRE, J. A. L. A Construção do Objeto Científico na Investigação Empírica. Cascavel: Fundação Universidade Estadual do Oeste do Paraná. 1991. Mimeo.

MC LAREN, P. A Vida nas Escolas: uma introdução à pedagogia crítica nos fundamentos da educação. 2 ed. Porto Alegre: Artes Médicas, 1997.

PERRENOUD, P. Avaliação: da excelência à regulação das aprendizagens - entre duas lógicas. Porto Alegre: ArtMed, 1999.

PERRENOUD, P. Dez Novas Competências Para Ensinar. Porto Alegre: ArtMed, 2000.

RICHARDSON, R. J. Pesquisa Social: métodos e técnicas. 3 ed. São Paulo: Atlas, 1999. p. 334.

SAMPAIO, H. Evolução do ensino superior brasileiro 1808-1990, NUPES/USP, São Paulo, 1991. 